\title{
Pitfalls in Posterior Fossa CT Scanning: An Illustrative Case Report
}

\author{
FRASER W. SAUNDERS and BRUCE 1. TR ANMER
}

SUMMARY: $A$ case is described that illustrates the difficulties involved with the interpretation of postoperative posterior fossa CT scans. The reasons for the difficulties are discussed and the pertinent literature reviewed.

RESUMÉ: Nous présentons une histoire de cas qui illustre les difficultés inhérentes $\grave{a}$ l'interprétation des tomodensitométries de la fosse postérieure. Nous discutons des raisons pour les difficultés et revovons la littérature pertinente.

From the Division of Neurological Surgery, Queens University and the Kingston General Hospital, Kingston, Ontario.

Reprint requests to Dr. F.W. Saunders. Division of Neurological Surgery, Kingston General Hospital, Kingston, Ontario, Canada, K $7 L 2 V 7$.

\section{INTRODUCTION}

This report describes a 24 year old man with a posterior fossa medulloblastoma. His postoperative course was instructive because of the discrepancies that developed between the CT scan interpretations and the operative findings. His case history will be presented and the findings discussed.

\section{PATIENT HISTORY}

This 24 year old man presented with headaches one month before admission. He progressed to an ataxic gait and this precipitated his admission to hospital. There were no cranial nerve abnormalities. His initial CT scan (GE Scanner - 8800) showed a midline posterior fossa mass (Figure 1), $\mathrm{He}$ was initially drained through a ventriculostomy, but the following day he had swallowing difficulty and problems with articulation. He was taken to the operating room where a midline superior vermis tumor was identified and removed. Histology was consistent with a medulloblastoma.

He did well for 24 hours, but then his level of consciousness decreased and he began to have difficulties with speech. An unenhanced $\mathrm{CT}$ scan was interpreted as showing no definitive evidence of a postoperative hematoma (Figure 2). He continued to deteriorate and underwent an emergency re-exploration. A large fresh blood clot was found in the old tumor bed and fourth ventricle. He again made a good recovery.

After placing a shunt for hydrocephalus two weeks following the second operation he again deteriorated. A repeat CT scan at that time showed an enhancing mass in the posterior fossa and this time showed an enhancing mass in the posterior fossa and this was suspected of being recurrent tumor (Figure 3, 4). After a great deal of discussion with the family, he was eventually re-explored and this was found to be a large cyst that contained high protein fluid. The cyst was drained with no particular difficulty.
Following this procedure, however, things did not go well. He remained with brainstem signs and this condition was complicated by pulmonary emboli. Over the next month, despite radiotherapy, he lapsed further into unconsciousness and died of ventilatory failure. At autopsy he had spread of the medulloblastoma through the entire spinal axis and his death was assumed to be on the basis of brainstem and spinal compression with ensuing hypoventilation.

\section{DISCUSSION}

This patient's postoperative course demonstrated two incidences where our interpretation of the CT scan was in error. In both cases operative reexploration revealed pathology that we did not expect to find. As one gets more experienced with the CT scanner, one realizes that it, like any other investigation, is only a test and one must take the final decision on the patient's clinical course.

This patient deteriorated approximately 24 hours after his initial surgery. The unenhanced $\mathrm{CT}$ scan shown in Figure 2 did not reveal an area of high absorption typical of a blood clot. Despite this, when he deteriorated further and was reexplored, a large blood clot was found. Blood usually gives an absorption coefficient in the range of 25 to 50 MU(u). C.S.F. on the other hand has an absorption co-efficient of between 0 and $10 \mathrm{MU}(\mathrm{u})$. The absorption coefficient that was seen in this case was between these two and was unable to be differentiated from normal cerebellum. Because of this the CT scan was initially interpreted as showing just postoperative cerebellar swelling. At re-exploration a mixture of C.S.F. and blood clot was found. It is hypothesized that the mixture of clotted blood and C.S.F. from the decompressed aqueduct resulted in the confusing 


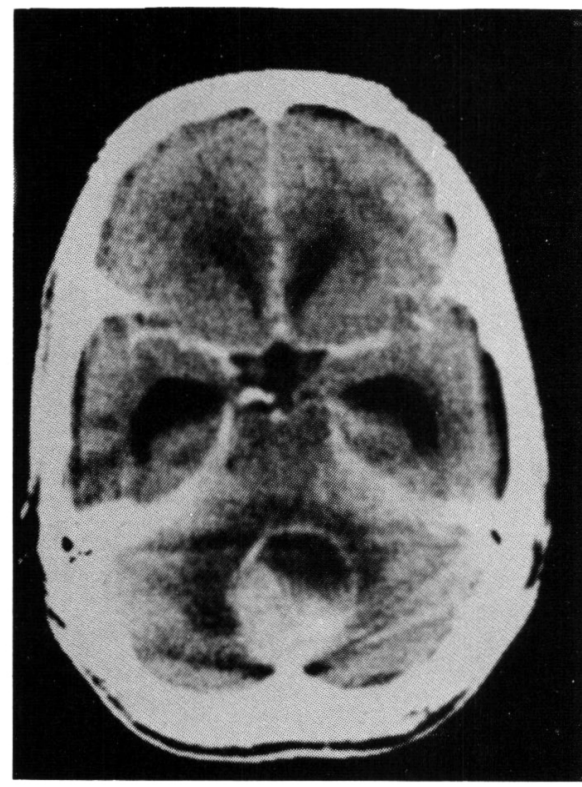

Figure 1 - Contrast enhanced scan shows large circular posterior fossa mass.

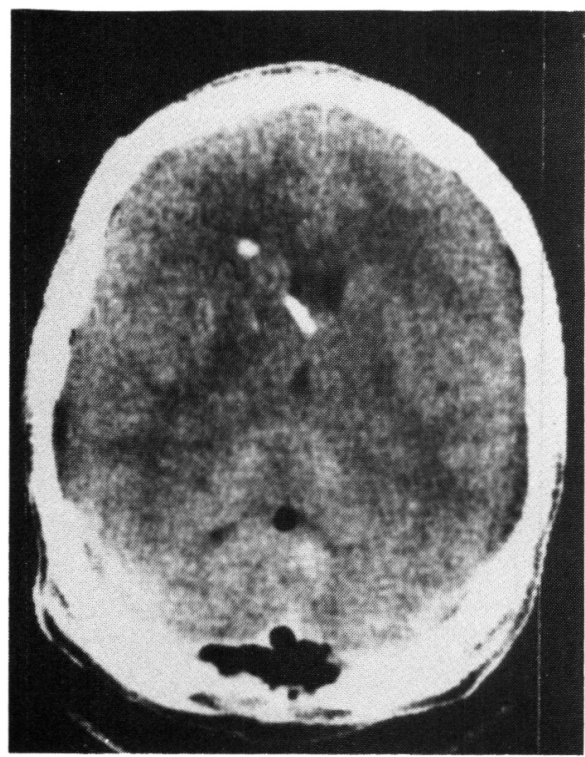

Figure 2 - Postoperative unenhanced scan showing air in the posterior fossa and no high absorption area that is typical of fresh blood clot.

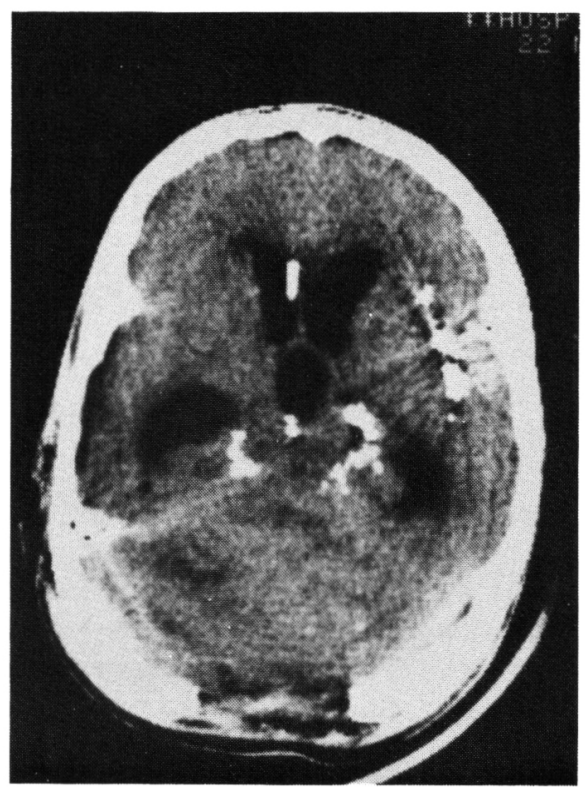

Figure 3 - Unenhanced scan showing only obliteration of the fourth ventricle.

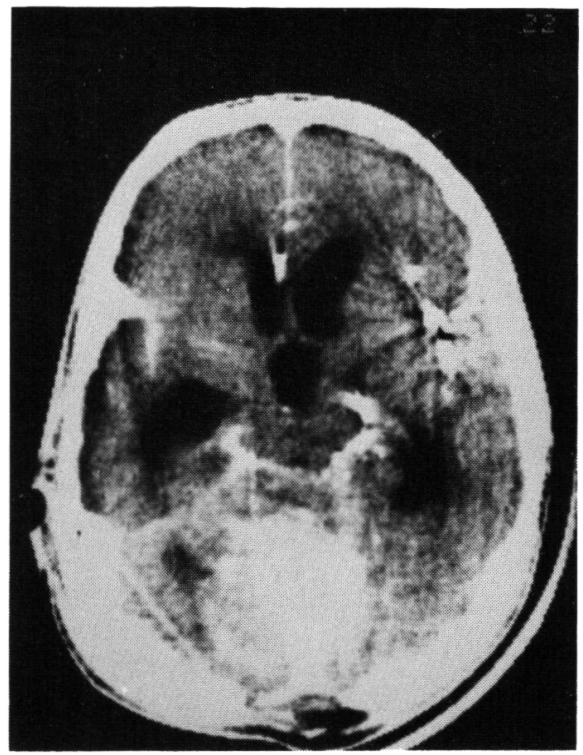

Figure 4 - Enhanced scan showing a large circular mass.

of the posterior fossa done at that time showed an enhancing circular mass (Figure 3,4). It was thought that this represented recurrent or persistent tumor. It was our initial tendency not to operate again. At surgery, however, a large cyst was entered which contained high protein fluid. We suspect that the C.S.F. was mixed with protein that leaked from the residual tumor. These two components gave an absorption co-efficient about equal to that of normal brain. The reason why such a cystic space should enhance is not clear. It would seem unlikely that the permeability of the tumor would be great enough or rapid enough to allow the escape of contrast into the cyst, but we have no other explanation for this.

The diagnostic specificity of the CT scanner is being questioned as more experience accumulates. The sign of peripheral enhancement has been shown to be nonspecific in several recent studies (Balsys et al., 1979; Spetzler et al., 1979). The realization that subdurals pass through a stage in which they are isodense with brain has been reported by Tsai et al. (1979). As the blood breaks down there is an associated decrease in absorption and in two to three weeks the values are close to that of the normal adjacent brain tissue. The only clues may be a ventricular shift or an early enhancing membrane. It almost goes without saying that for the CT scanner to show abnormalities the appropriate slices must be taken. Luetje (1979) has described small lesions, such as small acoustic neuromas, that have been overlooked in this manner.

\section{RESULTS}

This report emphasizes that the mixture of blood, C.S.F. and protein may give a confusing $\mathrm{CT}$ picture depending on the relative proportion of each. Realizing that the scanner may be misinterpreted, the clinical status of the patient shold be the final determinant of patient care.

\section{ACKNOWLEDGEMENTS}

We would like to thank Dr. R.A. deVilliers for letting us discuss his patient and Dr. W.J.S. Marshall for his help with the patient's care and discussion of the paper.

\section{REFERENCES}

ANGENENT, J.F.C., SCHENFELD, D.H.W. MALI, W.P. TH., VON WAES, P.F.G.M. (1979). Potential Pitfalls in Computer Tomography. Diagnostic Imaging 48: 326335.

BALSYS, RAYMOND, JANOVSEK, J.E., BAINITZKY, SOLOMEN, TEMPLETON, 
A.W. (1979). Peripheral Enhancement in Computerized Cranial Tomography: A Non-specific Finding. Surgical Neurology 11, 207-216.

LUETJE, CHARLES (1979). The CT Scan: Pitfalls and Posterior Fossa Cisternography.
Otolaryngology Head Neck Surgery 87: 266267.

SPETZLER, R.F., NORMAN, D., SELMAN, W.R., KAUFMAN, B., WILSON, C.B. (1979). Computerized Tomographic Diagnosis: Pitfalls for Neurosurgeons. Neuro- surgery, Vol. 5, No. 2. 23!-235.

TSAI, F.Y., HUPRICH, J.E., SEGALL, H.D.. TEAL, J.S. (1979). The Contrast-Enhanced CT Scan in the Diagnosis of Isodense Subdural Hematoma. Journal of Neurosurgery. 50: 64-69. 